\title{
Choosing an effective mobile health application to help manage Type 1 Diabetes Mellitus effectively
}

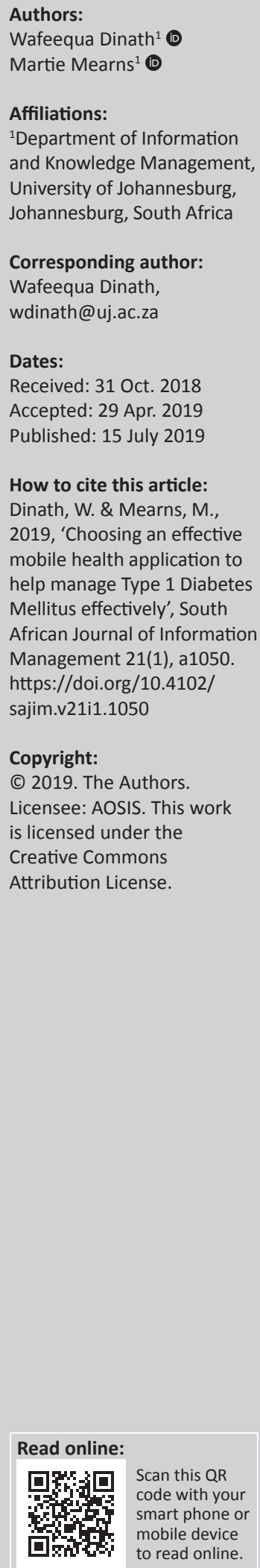

Background: The current era can be called a mobile health revolution as medical applications created for smartphones are flourishing in the market. Individuals living with Type 1 Diabetes Mellitus (T1DM) need to count carbohydrates, monitor blood glucose levels and determine insulin dosages.

Objective: By finding out which mobile health applications individuals living with diabetes are using to manage their illness effectively, a set of recommendations could be developed to support individuals who are less effective in managing their condition to use when choosing and using these specific mobile health applications.

Method: A qualitative research methodology was carried out to investigate how mobile health applications can assist individuals with managing diabetes more effectively. Evaluation criteria tools were used to rate specific mobile health applications for diabetes self-management, and focus group interviews were conducted to find out about the views, opinions and experiences of the individuals who used the mobile health applications.

Results: The findings showed that selecting the correct type of mobile health application to manage their diabetes better is possible. Based on this, recommendations were then developed for individuals to effectively use mobile health applications to help them manage their diabetes as well as recommendations for healthcare practitioners to encourage individuals to make use of mobile health applications and for application developers to improve their mobile health applications.

Conclusion: Recommendations for using mHealth apps effectively have been established to help individuals manage their T1DM, provided that the individual is committed to using the mobile health application correctly.

Keywords: Mobile health applications; Type 1 Diabetes Mellitus; diabetes self-management recommendations; healthcare practitioners; application developers.

\section{Introduction}

This research study investigated the use of mobile health applications (mHealth apps) as a tool for managing Type 1 Diabetes Mellitus (T1DM) effectively. Type 1 Diabetes Mellitus is a chronic illness that is widespread (Diabetes.co.uk 2019:1). The World Health Organization (WHO) estimated that T1DM was the seventh leading cause of death worldwide in 2016, and the statistics continue to rise (WHO 2019:1). In 2016, T1DM was the direct cause of 1.6 million deaths. Today there are numerous mHealth apps for smartphones that assist individuals, living with R1DM, in managing their illness better (Healio 2018:1). These mHealth apps can help individuals living with T1DM by providing nutritional advice, counting carbohydrates, logging blood glucose levels, notifying them when insulin dosages should be taken and helping them manage their illness by making more effective decisions (Thornby \& Edquist 2013:66). Thus, mobile communication is altering behavioural attitudes towards glucose levels, medication adherence and physical activity (Quinn 2011:16).

Previous research related to this study explores how mHealth apps can potentially enhance the health outcomes of individuals living with T1DM (Eysenbach 2011:1).Despite the technological success and progress of mHealth apps, they also raise concerns about issues such as regulation and approval, privacy, safety and accuracy. This study determined features that individuals can use to select appropriate mHealth apps to help them manage their illness effectively. mHealth apps exhibit remarkable functionality, versatility and usability at a minimal cost. New mHealth apps are emerging and becoming more refined and, in turn, could provide individuals with many more functions, which will eventually lead to effectively improving their illness (Tran, Tran \& 
White 2012:173). Thus, mHealth apps can encourage communication, information sharing and decision-making for individuals living with T1DM to help them manage their illnesses better (Goyal \& Cafazzo 2013:2).

\section{Mobile health applications}

Mobile technology is rapidly evolving to become more connected to users (Ross 2018:1). The 21st century can be called a 'mobile health revolution' as medical apps are flourishing in the marketplace. In addition, healthcare practitioners are continuously encountering questions regarding the value of such apps by patients (Eng \& Lee 2013:231). An mHealth app is intended for performing any kind of medical device functions such as diagnosing, curing, mitigating, treating or preventing an illness or disease (Cohen \& Zegarell 2017:1). mHealth apps have advantages and disadvantages for both health consumers and public.

Some of the advantages are that individuals become empowered because with mHealth apps they can monitor themselves, for example, by monitoring their heart rate, calorie intake, blood pressure and weight. By having these types of information, individuals can put general health recommendations into personal contexts. For example, if an individual is trying to get his or her heart rate in line with a cardiovascular target, then the individual can monitor how much weight needs to be lost and how much to exercise and eat (Kendall 2013:458). Some of the disadvantages are that individuals might not know which mHealth apps are appropriate for them, or they might misuse $\mathrm{mHealth}$ apps. For example, it is possible that a specific $\mathrm{mHealth}$ app could be measuring a particular aspect of an individual's health incorrectly, and this, in turn, will lead the individual to set unrealistic goals like trying to lose more weight than necessary (Kendall 2013:459).

Numerous mHealth apps are available for diabetes selfmanagement. Some are free and some are paid (Gordon 2014:1). mHealth apps can help individuals living with T1DM to manage their illnesses more effectively by providing nutritional advice, counting carbohydrates, monitoring blood glucose levels and sending alerts for taking medication (Gordon 2014:1). Globally, smartphone users have an average of 30 apps on their smartphones (Aitken 2013:4). The number of mHealth apps available at the top app stores worldwide increased substantially over the past 3 years. There were over 318000 mHealth apps to choose from in 2018; this is almost double the amount that was available in 2015 (Liquid State 2018:1).

\section{Potential of mobile health applications to enhance healthcare}

Regardless of the remarkable and constantly developing capabilities that mHealth apps possess, unless mobile app developers and the health community effectively incorporate these mHealth apps into the general healthcare system, they will only remain gadgets. Therefore, mHealth apps need to be able to communicate with various healthcare technologies and electronic health records to be effective (Schulke 2013:1705). mHealth apps are considered to still be in their infancy but with a significant amount of untapped potential. The reason for this is that a large percentage of these apps mainly focus on exercise and diet management as opposed to the management of illnesses (Schulke 2013:1709).

However, such mHealth apps can provide useful tools for users who want to become and stay healthy through eating and exercising correctly. Eating and exercising correctly is crucial to managing any type of chronic disease. Thus, these mHealth apps are valuable to the general well-being of users (Schulke 2013:1708). Certain mHealth apps are even able to transfer users' data directly to the required electronic health record system. In turn, healthcare practitioners can monitor the users' condition remotely, which reduces the time users need to physically visit their healthcare practitioners (Schulke 2013:1709). The possibilities of using mHealth apps in healthcare seem to be advantageous.

\section{The functionality of mobile health applications}

The term functionality in this study refers to functions that should be supported by a diabetes self-management mobile app to assist users in managing their illnesses more effectively. It is important to note that academic literature regarding functionality requirements for diabetes self-management using mHealth apps is limited (Arellano et al. 2012:10). Arellano et al. (2012:10) state that the most common features that mHealth apps possess for diabetes self-management are:

- To log blood glucose levels manually

- To be able to synchronise mHealth apps with glucose metres to download blood glucose levels automatically

- To generate and export statistics and graphs

- To log measures such as water consumption, insulin dosages, carbohydrate intake, physical activity, weight and blood pressure

- To determine the amount of glycated haemoglobin in the body

- To create reminders and notifications to perform certain tasks such as testing blood glucose levels and taking insulin

- To compute carbohydrates for certain kinds of foods to determine the amount of insulin to take.

Within existing research (Liang et al. 2011:455), it is stated that mHealth apps can potentially assist individuals living with T1DM to manage their illnesses more effectively. Thus, the first aim of this study was focused on harnessing experiences of 'committed individuals' with effectively using mHealth apps to find out which mHealth apps are enablers to support the effective management of T1DM.

From this research problem, the following objectives were thus identified:

- To identify which mHealth apps committed individuals are using to manage their T1DM 
- To investigate the features that committed individuals identify in their selection of effective mHealth apps

- To develop a set of recommendations that individuals can use to select mHealth apps to assist them in managing their T1DM more effectively.

To address the stated aims and objectives above, the following research question was formulated: What recommendations would enable individuals to utilise mHealth apps effectively to assist them in managing their T1DM?

To operationalise the research objectives, the following subquestions were used to address the research problem:

- What makes a committed individual and what forms the basis when choosing mHealth apps to help them manage their T1DM effectively?

- What mHealth app functionalities can best assist individuals living with T1DM to manage their illnesses more effectively?

The research for this study was conducted at a clinic in Gauteng, South Africa. A clinical physician, who has been specialising in T1DM for over 18 years, assisted the researcher with the data collection of this study.

\section{Research design and methods}

The ontological assumptions of this study, in particular, see interpretivism as appropriate. In relation to this study, the way the participants used the mHealth apps to help manage their T1DM was the central point. This study's research problem required an inductive approach. The purpose of collecting data through evaluation criteria tools and focus group interviews in this study was to identify features that the committed individuals used to choose appropriate mHealth apps to help manage their T1DM effectively. A qualitative approach was chosen for this study because the study was largely concerned with the subjective assessment of the participants' behaviour, attitudes and opinions. Openended data were collected for this study with the intention of deriving themes from the data. The process of qualitative research in this study involved emerging questions and procedures, data collected in the participant's setting, data analysis built from particular to general themes and the researcher's interpretation of the meaning of the data.

Therefore, a qualitative research methodological paradigm was adopted for this study to develop a set of recommendations that individuals can use, to select and use mHealth apps appropriately. Evaluation criteria tools and focus group interviews were used as qualitative data sources. Crosssectional studies, such as this particular study, seek to explain the incidences of phenomena. The data collected for this study were collected simultaneously. Therefore, adopting a crosssectional study was appropriate because this study made use of real-time data that were collected through evaluation criteria tools, reflection diaries and focus group interviews.

\section{Data collection}

After a careful analysis of a number of data collection tools, the data collection techniques that were selected for this study were focus group discussions and the completion of an evaluation criteria tool. Participants were asked to complete an evaluation criteria tool that was developed by Ben and Mearns (2014) using the features depicted in Table 1. The features are focused on the app's functionalities. The purpose of the evaluation criteria tool was to determine the effectiveness of the functionalities of the preferred mHealth apps used by the committed individuals. The evaluation criteria tool was appropriate because the participants themselves could effectively answer the study's evaluation questions and information needs. Concerning this present study, the focus was on assessing the views, opinions and experiences of the participants regarding the effectiveness of mHealth apps for managing T1DM.

TABLE 1: mHealth app evaluation criteria tool.

\begin{tabular}{|c|c|c|c|c|}
\hline Variable & Number & 3 & 2 & 1 \\
\hline Relevance & 1 & The app does what it claims it can do. & $\begin{array}{l}\text { The app only does a few things that it claims it } \\
\text { can do. }\end{array}$ & The app does not do what it claims it can do. \\
\hline Customisation & 2 & $\begin{array}{l}\text { The app allows me to alter settings and } \\
\text { content to my needs. }\end{array}$ & $\begin{array}{l}\text { The app allows me to partially alter settings and } \\
\text { content to my needs. }\end{array}$ & $\begin{array}{l}\text { The app does not allow me to alter settings } \\
\text { and content to my needs. }\end{array}$ \\
\hline \multirow[t]{3}{*}{ Feedback } & 3 & $\begin{array}{l}\text { The feedback from the app was relevant in } \\
\text { managing my medication correctly. }\end{array}$ & $\begin{array}{l}\text { The feedback from the app was reasonable in } \\
\text { managing my medication correctly. }\end{array}$ & $\begin{array}{l}\text { The feedback from the app was poor in } \\
\text { managing my medication correctly. }\end{array}$ \\
\hline & 4 & $\begin{array}{l}\text { The feedback from the app was relevant in } \\
\text { managing my diet correctly. }\end{array}$ & $\begin{array}{l}\text { The feedback from the app was reasonable in } \\
\text { managing my diet correctly. }\end{array}$ & $\begin{array}{l}\text { The feedback from the app was poor in } \\
\text { managing my diet correctly. }\end{array}$ \\
\hline & 5 & $\begin{array}{l}\text { The feedback from the app was relevant in } \\
\text { managing my exercise plan correctly. }\end{array}$ & $\begin{array}{l}\text { The feedback from the app was reasonable in } \\
\text { managing my exercise plan correctly. }\end{array}$ & $\begin{array}{l}\text { The feedback from the app was poor in } \\
\text { managing my exercise plan correctly. }\end{array}$ \\
\hline \multirow[t]{3}{*}{ Usability } & 6 & $\begin{array}{l}\text { I was able to launch the app without any } \\
\text { help. }\end{array}$ & I needed help to launch the app. & I was unable to launch the app. \\
\hline & 7 & $\begin{array}{l}\text { I was able to put data into the app } \\
\text { independently. }\end{array}$ & I needed assistance to put data into the app. & I was unable to put data into the app. \\
\hline & 8 & $\begin{array}{l}\text { I was able to use the app in an interactive } \\
\text { manner. }\end{array}$ & $\begin{array}{l}\text { I needed assistance to use the app in an } \\
\text { interactive manner. }\end{array}$ & $\begin{array}{l}\text { I was unable to use the app in an interactive } \\
\text { manner. }\end{array}$ \\
\hline Motivation to use & 9 & The app itself motivated me to use the app. & I required additional motivation to use the app. & I was not motivated to use the app. \\
\hline \multirow[t]{3}{*}{ Sharing of data } & 10 & $\begin{array}{l}\text { The app allowed me to easily share my data } \\
\text { with my doctor(s). }\end{array}$ & $\begin{array}{l}\text { I needed assistance to share my data with my } \\
\text { doctor(s). }\end{array}$ & $\begin{array}{l}\text { The app did not allow me to share my data } \\
\text { with my doctor(s). }\end{array}$ \\
\hline & 11 & $\begin{array}{l}\text { The app allowed me to easily send my data } \\
\text { to my email account. }\end{array}$ & $\begin{array}{l}\text { I needed assistance to send my data to my email } \\
\text { account. }\end{array}$ & $\begin{array}{l}\text { The app did not allow me to send my data to } \\
\text { my email account. }\end{array}$ \\
\hline & 12 & $\begin{array}{l}\text { The app allowed me to easily transfer my } \\
\text { data from my glucose metre to the app. }\end{array}$ & $\begin{array}{l}\text { I needed assistance to transfer my data from my } \\
\text { glucose metre to the app. }\end{array}$ & $\begin{array}{l}\text { The app did not allow me to transfer my data } \\
\text { from my glucose metre to the app. }\end{array}$ \\
\hline
\end{tabular}


The functionality category was chosen for the evaluation criteria tool because it was increasingly evident in the literature (Cafazzo, Casselman \& Hamming 2012; Bental \& Cawsey 2002; Eysenbach 2011). The heuristic evaluation method was used to evaluate an interface and evaluators usually measure the effectiveness, efficiency and usability of an interface (Clune 2009:5) as was also applied in the evaluation criteria tool depicted in Table 1.

Three focus groups consisting of 15 participants in total were used to collect further data for the study. The participants for focus group interviews are selected because they possess certain characteristics relating to the topic being discussed (Glesne 2006:102). Focus group interviews were conducted to gather the opinions, views and experiences of the committed individuals to establish recommendations that can be used to select mHealth apps to help manage T1DM effectively. The focus group interviews were audio recorded and then transcribed for analysis. The focus group interviews comprised of open-ended questions that allowed for detailed answers to be extracted from the participants in a study.

The sampling technique that was used in this study was convenience sampling because participants were selected based on aspects such as their accessibility and proximity to the researcher. However, it is important to note that a convenience sample is not representative of an entire population (Chrisler \& McCreary 2010:181). The sample size consisted of 15 participants who were already using mHealth apps to help manage their T1DM effectively. Possible participants were referred by their healthcare practitioners to participate in this study. The eligible participants were then briefed as to what the study was about. All the participants had to have already been using an mHealth app to manage their T1DM. To be included in this study, participants had to have been diagnosed with T1DM, participants needed to possess an active smartphone and participants needed to be committed to the use of mHealth apps, as well as be able to manage their illness effectively.

Participants that met the inclusion criteria but were advised by their healthcare practitioners not to partake in this study, as well as participants that could not obtain parental consent were excluded from the study. Ethical guidelines as prescribed by the participating healthcare practitioner and the institution from where the research was conducted was adhered to strictly and appropriately. Ethical considerations for the study included a letter of consent given to each participant that informed the participants about the purpose of this study, as well as how it could benefit them. Only participants who were advised to participate in this study by their healthcare practitioners were approached and included. In addition, participants that were under the age of 18 needed a parent or guardian to complete the consent form on their behalf, personal information about the participants was kept confidential.

The preferred mHealth apps that the committed individuals were using were used in this study. Each participant used their preferred mHealth app for 1 month, rated the app's functionalities by using the evaluation criteria tool and attended a focus group interview to discuss their perceptions and experiences regarding the recommendations that could be used to select an app to manage T1DM effectively.

\section{Ethical consideration}

This study was cleared by the University of Johannesburg's ethical committee. Permission was also granted from the clinic at which this study was carried out at and consent forms were completed by all participants.

\section{Results}

The data gathered from the focus group interviews, which the committed individuals attended, were analysed using thematic analysis. Various themes were identified and then recommendations were established based on these results to assist those people living with T1DM to select appropriate mHealth apps to help them manage their illnesses more effectively. Features for selecting appropriate mHealth apps to help manage T1DM were investigated as the aim of this study.

\section{Mobile health applications used by the committed individuals}

The four mHealth apps that were used by the committed individuals were Glucose Buddy, On-Track Diabetes, Sugar Sense and dbees.com. In Figure 1, the features that are shaded in green come standard with the specific mHealth app, the features that are shaded in orange require users to make an inapp purchase to activate the feature and the features that are shaded in blue are not available on the specific mHealth app.

\section{Evaluation criteria tool findings}

Figure 2 depicts the findings from the evaluation criteria tools that the committed individuals used to rate the features of their preferred mHealth apps. The numbers entered in Figure 2 represent the number of participants that selected each feature. Figure 2 is colour coded; red represents Glucose Buddy, green represents On-Track Diabetes, yellow represents Sugar Sense and blue represents dbees.com. Hence, all 15 participants claimed that their preferred mHealth apps were:

- relevant in helping them manage their T1DM,

- able to provide them with appropriate feedback relating to medication, diet and exercise,

- allowed them to put data into, and use the app effectively,

- motivated them to use the app, and

- allowed them to share data with their family and healthcare professionals through email.

However, the data gathered also showed that there was difficulty in launching the dbees.com app as users first needed to register online to retrieve a password to activate the mHealth app. Lastly, out of the four mHealth apps, only Sugar Sense allowed users to automatically transfer their blood glucose readings from their glucose metres onto the app. However, a specific type of glucose metre is required, and none of the participants were in possession of this 


\begin{tabular}{|c|c|c|c|c|}
\hline Features & Glucose buddy & $\begin{array}{l}\text { On-track } \\
\text { diabetes }\end{array}$ & Sugar sense & dbees.com \\
\hline & $\left(\begin{array}{c}-120 \\
86\end{array}\right.$ & & & dbees \\
\hline \multicolumn{5}{|l|}{ A1c estimator } \\
\hline \multicolumn{5}{|l|}{\begin{tabular}{|l} 
Calorie \\
counter
\end{tabular}} \\
\hline \multicolumn{5}{|l|}{\begin{tabular}{|l|} 
Activity log \\
\end{tabular}} \\
\hline \multicolumn{5}{|l|}{ Food log } \\
\hline \multicolumn{5}{|l|}{ Glucose log } \\
\hline \multicolumn{5}{|l|}{ Graphs } \\
\hline \multicolumn{5}{|l|}{\begin{tabular}{|l|} 
Insulin dose \\
log
\end{tabular}} \\
\hline \multicolumn{5}{|l|}{\begin{tabular}{|l|} 
Weight log \\
\end{tabular}} \\
\hline \multicolumn{5}{|c|}{\begin{tabular}{|l|}
$\begin{array}{l}\text { Blood pressure } \\
\text { log }\end{array}$ \\
\end{tabular}} \\
\hline \multicolumn{5}{|l|}{\begin{tabular}{|l|} 
E-mail reports \\
\end{tabular}} \\
\hline \multicolumn{5}{|l|}{ Note field } \\
\hline \multicolumn{5}{|l|}{\begin{tabular}{|l|} 
Reminders \\
\end{tabular}} \\
\hline Compatibility & $\begin{array}{l}\text { Android, } \\
\text { iPhone, } \\
\text { iPod touch, } \\
\text { iPad }\end{array}$ & $\begin{array}{l}\text { Android, } \\
\text { iPhone, } \\
\text { Blackberry }\end{array}$ & $\begin{array}{l}\text { Android, } \\
\text { iPhone, } \\
\text { iPod touch, } \\
\text { iPad }\end{array}$ & $\begin{array}{l}\text { Android, JAVA, } \\
\text { iPhone, } \\
\text { Windows } \\
\text { mobile, } \\
\text { Symbian, } \\
\text { Blackberry }\end{array}$ \\
\hline $\begin{array}{l}\text { Special } \\
\text { features }\end{array}$ & $\begin{array}{l}\text { Synchronise } \\
\text { with online } \\
\text { account. } \\
\text { Follow glucose } \\
\text { buddy on } \\
\text { twitter and } \\
\text { facebook. }\end{array}$ & $\begin{array}{l}\text { Customisable } \\
\text { target ranges. } \\
\text { Colour coded } \\
\text { graphs. }\end{array}$ & $\begin{array}{l}\text { Works in } \\
\text { conjunction } \\
\text { with other } \\
\text { health apps } \\
\text { and devices. } \\
\text { Online } \\
\text { community. } \\
\text { Health guide } \\
\text { for keeping fit } \\
\text { and eating } \\
\text { well. }\end{array}$ & $\begin{array}{l}\text { Synchronise } \\
\text { with online } \\
\text { account. } \\
\text { Interactive } \\
\text { forum. }\end{array}$ \\
\hline Stand & & In-app purchas & & vailable \\
\hline
\end{tabular}

FIGURE 1: Features of the mHealth apps used by the committed individuals.

glucose metre. Therefore, data about this feature remain inconclusive. Nevertheless, the focus group findings revealed a number of themes relevant towards understanding the committed individuals' use of the mHealth app.

\section{Focus group interview findings}

The findings from the focus group interviews that the committed individuals attended were intended to establish features that individuals can use to choose appropriate $m$ Health apps to help manage their T1DM effectively. The length of time that these participants were using these apps for, the reasons as to why they started using the apps and the features that they liked and disliked about their preferred mHealth apps are summarised in Figure 2 below. Out of the 15 committed individuals, 4 of the participants had been using their apps for 6 months or less, 6 participants for between 7 and 12 months, 4 of the participants for between 13 and 18 months and one of the participants for between 19 and 24 months.

The 15 committed individuals stated the following seven reasons to use mHealth apps to help manage their T1DM effectively:

- Easy and fun to use

- Convenience
- Glucose control

- Fast and discreet transactions

- Recommendations

- Overcoming decision inertia

- Information sharing

Listed below are the features that the 15 committed individuals liked the most about their preferred mHealth apps:

- Easy and convenient to use

- Sharing information

- Reminders and push notifications

- Assists with decision-making

The 15 committed individuals liked the following features the least about their preferred mHealth apps:

- Tutorials about how to use mHealth apps are vague.

- Only certain mHealth apps are compatible with specific glucose metres.

- Reminders and push notifications become annoying.

- Full versions of certain mHealth apps require a fee to be paid.

The evaluation criteria tool focused mostly on technical aspects such as customisation, feedback options, usability and sharing of data. From the thematic analysis of the focus group discussions, features discussed below were identified in addition to the evaluation criteria tool as reflected in Table 1. The features discussed below should be incorporated into the evaluation criteria tool as they have been identified to be helpful in assisting a user to select an mHealth app specific to T1DM management. Features that committed individuals indicated as necessary to look out for when choosing mHealth apps were indicated to be monitoring of blood glucose levels to be easier and simpler, guidelines towards insulin dosages, decision-making and problem-solving skills support, providing feedback and share information, food and activity choices. Each of these are discussed in more detail based on the discussions that committed individuals had during the focus group interviews.

\section{Monitoring blood glucose levels in an easier and simpler way}

Daily self-monitoring of blood glucose levels provides individuals, living with T1DM, with the information they need to assess how medication, food and physical activity affect their blood glucose levels. Monitoring, however, does not stop there. Individuals living with T1DM also need to monitor their blood pressure, weight, urine and ketones regularly. In turn, individuals will learn about equipment choices and selection, timing and frequency of testing, target values and interpretation of results. mHealth apps that allow users to record their glucose readings in a manner that is easy and simple will drive the motivation to keep doing so.

When users are constantly recording and monitoring their blood glucose levels, they will be able to depict trends in their 


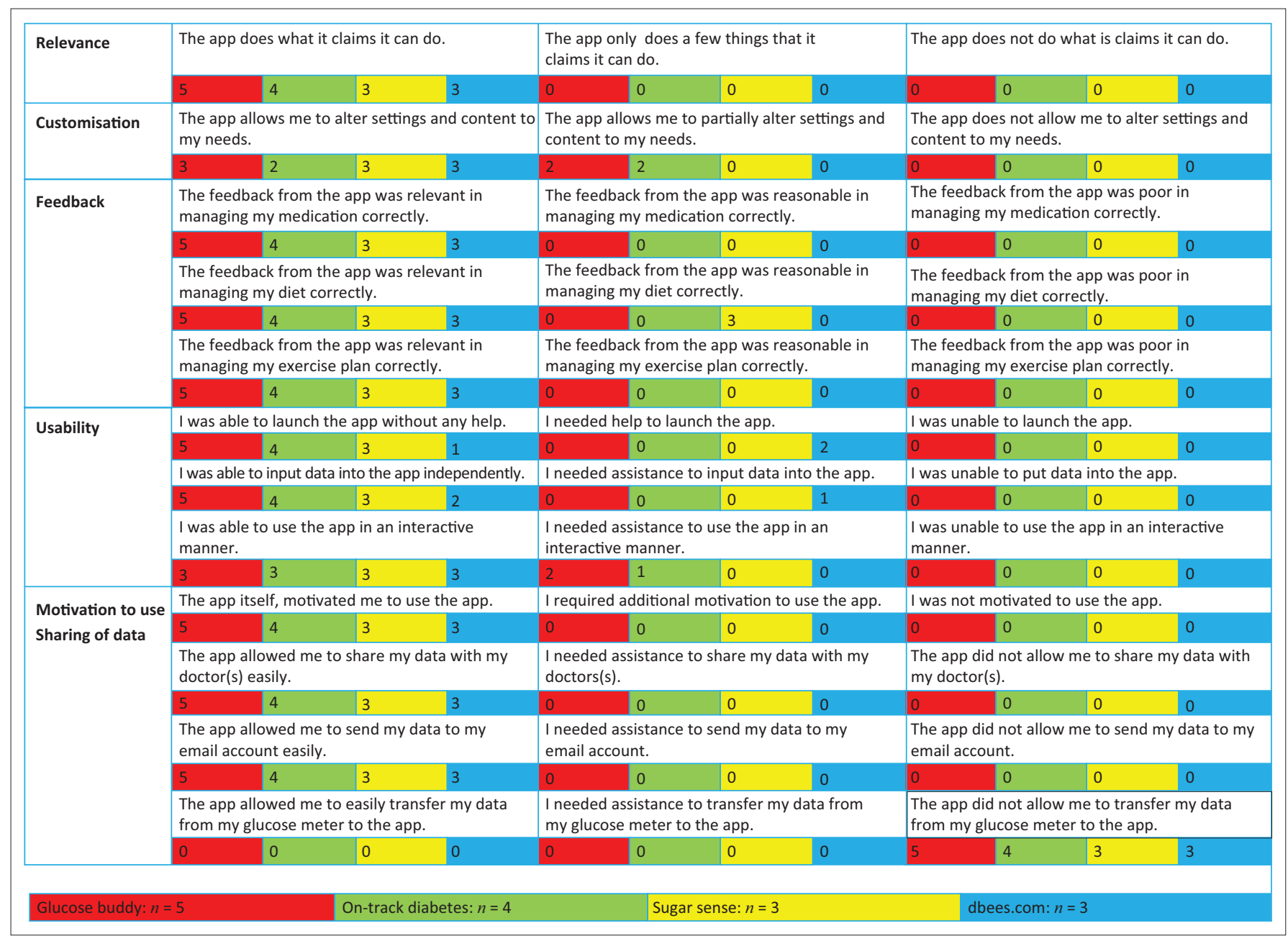

FIGURE 2: Evaluation criteria tool.

glucose levels, make decisions regarding the management of their T1DM, as well as know what information should be shared with their healthcare practitioners for valuable feedback. Therefore, individuals should select mHealth apps that will allow them to record their glucose readings easily, display any trends and patterns over time about the readings so that they can be pro-active. In turn, they will be able to make the necessary decisions, as well as allow users to share the information stored with their healthcare practitioners and family members for valuable feedback as discussed in the focus group findings.

\section{Guide insulin dosages}

Type 1 Diabetes Mellitus is a progressive condition. Depending on what type an individual has, their healthcare team will be able to determine which medications they should be taking and help them understand how different medications work (Diabetes Coalition 2016:1). The healthcare team can demonstrate how they should inject insulin, and how insulin works, as well as when to administer insulin. Taking the correct amount of insulin in combination with healthy lifestyle choices can lower blood glucose levels, as well as reduce the risk for diabetes complications. The goal is for individuals with T1DM to be knowledgeable about each type of insulin, including its action, side effects, effectiveness, toxicity, prescribed dosage, appropriate timing, frequency of administration, effect of delayed and missed dosages and instructions for storage, safety and travel (Diabetes Coalition 2016:1).

MHealth apps that are able to recommend how much insulin to take, based on blood glucose levels, are an advantage because individuals often miscalculate the amount of insulin they should take and, in turn, either inject too little or too much insulin. The result of this is the mismanagement of T1DM leading individuals to fall ill. Therefore, if the mHealth app is able to recommend the dose of insulin that should be taken based on glucose readings, individuals will be able to learn why, when and how much insulin to take.

\section{Decision-making and problem-solving skills support}

Individuals living with T1DM need to be pro-active when managing their illness. They need to be able to make decisions based on their glucose readings regarding what to eat, how much insulin to take and how much to exercise. In addition, individuals living with T1DM must also keep their problemsolving skills sharp because on any given day, a low or high blood glucose episode or a sick day will require them to make rapid and informed decisions about food, medications and activity (Diabetes Coalition 2016:1). This skill is continuously put to use because even after decades of living with the 
disease, steadiness is never fully attained: the disease is progressive, chronic complications emerge, life situations change and the patient ages.

mHealth apps that are able to suggest to users the amount of insulin to take when their glucose levels are in a certain range, as well as make recommendations regarding how much food to consume before engaging in physical activities, are invaluable. In addition, mHealth apps that are able to teach users about why certain things should be done, as well as the advantages and disadvantages of doing these things, are preferred. There is no point in instructing an individual to do something if the individual does not understand why they should be doing it.

\section{Provide feedback and share information}

Receiving feedback about the manner in which an individual manages their T1DM is significant because it helps the individual learn what should be done, as well as what should not be done. Being able to share information about one's illness with healthcare practitioners and family members is also important because valuable feedback can be provided. MHealth apps that provide real-time feedback about why glucose readings are in a certain range, for example, are beneficial because they will allow users to take the necessary action to rectify the glucose reading in the future. In addition, mHealth apps that allow users to share information with their healthcare practitioners and family members also make available feedback that might be needed instantaneously.

\section{Food choices}

Making healthy food choices, understanding portion sizes and learning the best times to eat are vital for managing T1DM. By making suitable food choices, children and teenagers grow and develop as they would if they did not have T1DM (Diabetes Coalition 2016:1). In addition, by controlling their weight and achieving favourable blood glucose levels, many adults may be able to manage their condition for a time without medication. MHealth apps that provide information about the effect of food on blood glucose levels, sources of carbohydrates, sources of fat and appropriate meal planning are significant. This in turn teaches individuals skills such as reading labels, measuring foods for portion control, fat control, planning and preparing meals and carbohydrate counting. With information provided on mHealth apps, individuals can plan food choices.

\section{Being active}

Regular physical activity is important for overall fitness, blood glucose control and weight management. With suitable levels of exercise, individuals living with T1DM can improve their glycaemic control. Being active can also help improve body mass index (BMI), enhance weight loss, help control blood pressure and reduce stress. In turn, individuals will be able to develop an appropriate activity plan that balances food and medication with their activity levels. mHealth apps that help users keep track of the impact that certain physical activities have on their blood glucose levels are key. In addition, apps that are able to recommend how much physical activity to engage in, as well as how much to eat prior to and after exercising are beneficial. This will help users avoid exercising too much or eating too little before exercising. Therefore, individuals can choose appropriate mHealth apps to help them with managing their T1DM by using the above features.

Below is the revised evaluation criteria tool (Table 2). It is, however, important to note that Arellano et al. (2012:10) stated that mHealth apps for diabetes self-management possess certain features that are of value for managing T1DM, as well as additional features that are of value for individuals to manage their T1DM effectively. In relation to the findings, the committed individuals have described the most common features as features that individuals should look out for when choosing mHealth apps. However, two of the features that Arellano et al. (2012:10) stated as features that will be of value to individuals seem to have not been features of the mHealth apps that were used in this study. They are allowing individuals to earn rewards for logging their blood glucose levels and learning about T1DM through quizzes, games and videos. Therefore, this area will have to be investigated further as the findings in this study are not clear on how this matter would influence committed individuals in their mHealth app choices.

\section{Discussion}

By addressing each of the formulated research questions, this study was successful in answering each of the research objectives. The views, opinions and perceptions of the 15 committed individuals living with T1DM and how they use mHealth apps to help manage their illness effectively were assessed. Thus, it was established that individuals who find it difficult to manage T1DM can use mHealth apps to help them manage their illness more effectively. Each of the objectives are synthesised below by indicating how they have been addressed through the research findings.

\section{Objective one: mHealth apps used by the committed individuals to manage their T1DM}

Committed individuals were described as individuals who can effectively utilise mHealth apps to help them manage their T1DM, and an mHealth app was defined as 'a software application that is designed to run on smartphones and tablet computers' (Aitken 2013:4). A convenience sample of 15 committed individuals was chosen with the help of the clinic. Focus group interviews were then conducted to find out which mHealth apps are enablers to support the effective management of T1DM. The four mHealth apps that the committed individuals were using were identified as Glucose Buddy, On-Track Diabetes, Sugar Sense and dbees.com. These four apps were discussed and in turn prepared the investigation for addressing the second research objective of the study. 
TABLE 2: Revised evaluation criteria tool for selecting mHealth apps.

\begin{tabular}{|c|c|c|c|c|}
\hline Variable & Number & 3 & 2 & 1 \\
\hline \multicolumn{5}{|l|}{ Technological aspects } \\
\hline \multirow[t]{3}{*}{ Usability } & 1 & I was able to launch the app independently. & I needed help to launch the app. & I was unable to launch the app. \\
\hline & 2 & $\begin{array}{l}\text { I was able to put data into the app } \\
\text { independently. }\end{array}$ & I needed help to put data into the app. & I was unable to put data into the app. \\
\hline & 3 & $\begin{array}{l}\text { I was able to use the app in an interactive } \\
\text { manner. }\end{array}$ & $\begin{array}{l}\text { I needed help to use the app in an interactive } \\
\text { manner. }\end{array}$ & $\begin{array}{l}\text { I was unable to use the app in an interactive } \\
\text { manner. }\end{array}$ \\
\hline Tutorials & 4 & $\begin{array}{l}\text { The tutorials for the app were easy to } \\
\text { understandable. }\end{array}$ & $\begin{array}{l}\text { The tutorials for the app were moderate to } \\
\text { understandable. }\end{array}$ & $\begin{array}{l}\text { The tutorials for the app were difficult to } \\
\text { understand. }\end{array}$ \\
\hline Customisation & 5 & $\begin{array}{l}\text { The app allowed me to alter settings and } \\
\text { content to my needs. }\end{array}$ & $\begin{array}{l}\text { The app allowed me to partially alter settings } \\
\text { and content to my needs. }\end{array}$ & $\begin{array}{l}\text { The app did not allow me to alter settings } \\
\text { and content to my needs. }\end{array}$ \\
\hline $\begin{array}{l}\text { Reminders and push } \\
\text { notifications }\end{array}$ & 6 & $\begin{array}{l}\text { The reminders and push notifications of } \\
\text { the app were customisable and effective. }\end{array}$ & $\begin{array}{l}\text { The reminders and push notifications of the app } \\
\text { were partially customisable and effective. }\end{array}$ & $\begin{array}{l}\text { The reminders and push notifications of the } \\
\text { app were neither customisable nor effective. }\end{array}$ \\
\hline In-app purchases & 7 & $\begin{array}{l}\text { There were no in-app purchases to activate } \\
\text { additional features of the app. }\end{array}$ & $\begin{array}{l}\text { There were some in-app purchases to activate } \\
\text { additional features of the app. }\end{array}$ & $\begin{array}{l}\text { There were a lot of in-app purchases to } \\
\text { activate additional features of the app. }\end{array}$ \\
\hline $\begin{array}{l}\text { Compatibility with } \\
\text { glucose meters }\end{array}$ & 8 & $\begin{array}{l}\text { The app could connect to my glucose } \\
\text { meter. }\end{array}$ & $\begin{array}{l}\text { I needed help to connect the app to my glucose } \\
\text { meter. }\end{array}$ & $\begin{array}{l}\text { The app could not connect to my glucose } \\
\text { meter. }\end{array}$ \\
\hline Improved usage skill & 9 & $\begin{array}{l}\text { My skills for using the app improved over } \\
\text { time. }\end{array}$ & $\begin{array}{l}\text { My skills for using the app only improved a little } \\
\text { over time. }\end{array}$ & $\begin{array}{l}\text { My skills for using the app did not imoprove } \\
\text { over time. }\end{array}$ \\
\hline \multicolumn{5}{|l|}{ Health management } \\
\hline Blood glucose levels & 10 & $\begin{array}{l}\text { The app assisted me with controlling my } \\
\text { blood glucose levels. }\end{array}$ & $\begin{array}{l}\text { The app partially assisted me with controlling my } \\
\text { blood glucose levels. }\end{array}$ & $\begin{array}{l}\text { The app did not assist me with controlling my } \\
\text { blood glucose levels. }\end{array}$ \\
\hline Insulin dosages & 11 & $\begin{array}{l}\text { The app helped me to calculate how much } \\
\text { insulin to administer. }\end{array}$ & $\begin{array}{l}\text { The app partially helped me to calculate how } \\
\text { much insulin to administer. }\end{array}$ & $\begin{array}{l}\text { The app did not help me to calculate how } \\
\text { much insulin to administer. }\end{array}$ \\
\hline Discrete transactions & 12 & The app offered me discrete transactions. & The app partially offered me discrete transactions. & The app did not offer me discrete transactions. \\
\hline \multirow[t]{3}{*}{$\begin{array}{l}\text { Feedback and } \\
\text { recommendations }\end{array}$} & 13 & $\begin{array}{l}\text { The feedback from the app was relevant in } \\
\text { managing my medication correctly. }\end{array}$ & $\begin{array}{l}\text { The feedback from the app was reasonable in } \\
\text { managing my medication correctly. }\end{array}$ & $\begin{array}{l}\text { The feedback from the app was poor in } \\
\text { managing my medication correctly. }\end{array}$ \\
\hline & 14 & $\begin{array}{l}\text { The feedback from the app was relevant in } \\
\text { managing my diet correctly. }\end{array}$ & $\begin{array}{l}\text { The feedback from the app was reasonable in } \\
\text { managing my diet correctly. }\end{array}$ & $\begin{array}{l}\text { The feedback from the app was poor in } \\
\text { managing my diet correctly. }\end{array}$ \\
\hline & 15 & $\begin{array}{l}\text { The feedback from the app was relevant in } \\
\text { managing my exercise plan correctly. }\end{array}$ & $\begin{array}{l}\text { The feedback from the app was reasonable in } \\
\text { managing my exercise plan correctly. }\end{array}$ & $\begin{array}{l}\text { The feedback from the app was poor in } \\
\text { managing my exercise plan correctly. }\end{array}$ \\
\hline Decision-making inertia & 16 & $\begin{array}{l}\text { The app helped me make pro-active } \\
\text { decisions about managing my illness. }\end{array}$ & $\begin{array}{l}\text { The app partially helped me make pro-active } \\
\text { decisions about managing my illness. }\end{array}$ & $\begin{array}{l}\text { The app did not help me make pro-active } \\
\text { decisions about managing my illness. }\end{array}$ \\
\hline Food choice support & 17 & $\begin{array}{l}\text { The app helped me choose the correct } \\
\text { food to eat. }\end{array}$ & $\begin{array}{l}\text { The app partially helped me to choose the correct } \\
\text { food to eat. }\end{array}$ & $\begin{array}{l}\text { The app did not help me choose the correct } \\
\text { food to eat. }\end{array}$ \\
\hline Activity support & 18 & $\begin{array}{l}\text { The app helped me choose exercise } \\
\text { activities to carry out. }\end{array}$ & $\begin{array}{l}\text { The app partially helped me choose exercise } \\
\text { activities to carry out. }\end{array}$ & $\begin{array}{l}\text { The app did not help me choose exercise } \\
\text { activities to carry out. }\end{array}$ \\
\hline \multirow[t]{2}{*}{ Sharing of data } & 19 & $\begin{array}{l}\text { The app allowed me to easily send my data } \\
\text { to recipients through email. }\end{array}$ & $\begin{array}{l}\text { I needed help to send my data to recipients } \\
\text { through email. }\end{array}$ & $\begin{array}{l}\text { The app did not allow me to send my data to } \\
\text { recipients through email. }\end{array}$ \\
\hline & 20 & $\begin{array}{l}\text { The app allowed me to easily upload my } \\
\text { data onto social networking platforms. }\end{array}$ & $\begin{array}{l}\text { I needed help to upload my data onto social } \\
\text { networking platforms. }\end{array}$ & $\begin{array}{l}\text { The app did not allow me to upload my data } \\
\text { onto social networking platforms. }\end{array}$ \\
\hline \multicolumn{5}{|l|}{ Convenience } \\
\hline $\begin{array}{l}\text { Convenient and simple } \\
\text { to use }\end{array}$ & 21 & The app was convenient and simple to use. & $\begin{array}{l}\text { Only certain features of the app were convenient } \\
\text { and simple to use. }\end{array}$ & $\begin{array}{l}\text { The app was not convenient and simple } \\
\text { to use. }\end{array}$ \\
\hline Easy and fun to use & 22 & The app was easy and fun to use. & $\begin{array}{l}\text { Only certain features of the app were easy and } \\
\text { fun to use. }\end{array}$ & $\begin{array}{l}\text { The app was difficult and not fun } \\
\text { to use. }\end{array}$ \\
\hline Relevance & 23 & The app did what it claimed it could do. & $\begin{array}{l}\text { The app only did a few things that it claimed it } \\
\text { could do. }\end{array}$ & $\begin{array}{l}\text { The app did not do what it claimed it } \\
\text { could do. }\end{array}$ \\
\hline Speed of transactions & 24 & $\begin{array}{l}\text { The speed of the transactions of the } \\
\text { app was fast. }\end{array}$ & $\begin{array}{l}\text { The speed of the transactions of the app was } \\
\text { moderate. }\end{array}$ & $\begin{array}{l}\text { The speed of the transactions of the app } \\
\text { was slow. }\end{array}$ \\
\hline Motivation to use & 25 & $\begin{array}{l}\text { The app itself, motivated me to use } \\
\text { the app. }\end{array}$ & I required additional motivation to use the app. & I was not motivated to use the app. \\
\hline
\end{tabular}

\section{Objective 2: mHealth app features that influenced the committed individuals' selection}

To investigate the features that committed individuals identified in their selection of effective mHealth apps, the features were tested to determine whether these features were helpful in choosing appropriate $\mathrm{mHealth}$ apps to help individuals manage their T1DM more effectively. The features that were established were derived from the findings of the evaluation criteria tool developed in a previous study (Ben \& Mearns 2014), as well as focus group interviews. These focus group interviews were conducted with the committed individuals to establish the features that they used to select their mHealth apps.

After analysing the data gathered from the focus group interviews using thematic analysis, the following themes were derived to develop a list of additional features. Individuals living with T1DM can use this list of features to select mHealth apps to help them manage their illness effectively, which is depicted in Figure 1. It was summarised that individuals living with T1DM may use the set of features identified by the committed individuals to support their selection process of the mHealth apps in order to help them manage their illness more effectively.

\section{Recommendations and areas for future research}

This research study has a dual purpose. Healthcare practitioners may use the recommendation from this study to support their patients with using mHealth apps to manage their diabetes effectively. App developers may use the 
recommendations from this study to develop effective mHealth apps for diabetes self-management.

\section{Recommendations for healthcare practitioners}

Many healthcare practitioners are unfamiliar with using mHealth apps effectively or are uncertain of which ones to prescribe to their patients. Therefore, healthcare practitioners and patients need to identify and use the correct mHealth apps. Healthcare practitioners may use the following recommendations to support their patients using mHealth apps for managing T1DM.

Healthcare practitioners may test different apps themselves and see which ones are more effective so that they are in a better position to advise and support their patients through using this technology. When healthcare practitioners consult with patients and parents of minor patients who are already using mHealth apps, they can determine how effectively they are managing their illness with the use of these apps and continuously guide them to better maintain a healthy lifestyle. Healthcare practitioners can also search and download different mHealth apps to build up a repository of apps and then make suggestions to their patients that are struggling.

Healthcare practitioners can advise patients that are not already using apps to use them and discuss the benefits of using them, as well as share information and discuss the use of mHealth apps with other healthcare practitioners in order to compare findings and results to build a knowledge base for the use and improvement of mHealth apps. Lastly, longitudinal research is necessary to measure the actual impact of using mHealth apps and healthcare practitioners should assess the value of the long-term use of mHealth apps on the healthcare of their T1DM patients.

\section{Recommendations for app developers}

Continuously using an app leads to effectively using an app. Therefore, app developers should develop apps that are able to connect to other apps because the majority of mHealth apps for diabetes self-management are not able to connect with other types of apps that go beyond sharing data to social networking sites or through email. A disadvantage of this is that data from other apps cannot be integrated into the mHealth app in use. This, in turn, requires users to enter the same data into their different apps, which eventually becomes monotonous. In addition, this disadvantage is also the cause of users giving up on the app shortly after downloading it.

If app developers can integrate features into their apps that make remote consultation possible, then mHealth apps could potentially reduce cost especially in chronic care. Data security, on the other hand, is increasingly becoming a significant issue in all aspects of everyday life. When users know that their personal information is protected, they will be comfortable with using the app. App developers need to continuously work on data security and inform users regularly about what they are doing to secure their data. Lastly, app developers need to work with healthcare practitioners to access the records of patients so that they can have access to medical databases.

The findings of this study could therefore be used as a guideline for individuals who find it difficult to manage their T1DM, to do so more effectively, using mHealth apps. Healthcare practitioners may resort to this study as a guideline to encourage their patients to use mHealth apps to make managing their T1DM easier, and app developers may put this study as a guideline for effectively developing mHealth apps for individuals living with T1DM. Considering the limitation to this study, areas for future research is also discussed. Within the research design, there are limitations that need to be declared in terms of the research choices made. The research design required that a small sample is used, although the sample was studied in-depth. Generalisations are therefore affected because of the small number of participants involved in the study. As a result, only a select amount of mHealth apps could be reviewed due to only using those that the participants were familiar with. Even though the sample delivered the required objectives for the study, areas for further research are recommended.

\section{Areas for future research}

From all the sources consulted to write up the literature review for this research study, it was evident that a lot of authors wrote about the benefits of using mHealth apps as opposed to how mHealth apps can be used effectively to manage T1DM. Therefore, research may be conducted about the efficacy of the use of mHealth apps in managing T1DM. Two of the features that have been found in this research study to be of value are not actual features of the mHealth apps that were used in this study, these features can be viewed in Table 2. They are 'allowing individuals to earn rewards for logging their blood glucose levels' and 'learning about T1DM through quizzes games and videos'. Therefore, this area will have to be investigated further as the findings were not clear on this matter. In addition, research can be conducted on the impact of how healthcare practitioners are able to encourage their patients to utilise mHealth apps, as well as about how app developers can develop apps that possess features that the users prefer. These points are explained in more detail under recommendations. Much larger samples would be needed for studies of this nature.

\section{Conclusion}

The final conclusions reached, based on this study, are that features for choosing recommendations for using $\mathrm{mHealth}$ apps effectively, may be established to help individuals manage their T1DM, provided that the individual is committed to using the mHealth app correctly. Problems that individuals are encountering with managing their T1DM such as monitoring blood glucose levels, administering the correct dosage of insulin, exercising and eating healthily need to be identified to find a suitable app. By identifying the problem area, an appropriate mHealth app can be chosen that will address the problem. Therefore, individuals who 
are committed to using mHealth apps to help manage their T1DM will more likely succeed in doing so. In turn, T1DM will be better managed, and long-term complications that arise from neglecting to manage this illness appropriately, can be eliminated, ensuring a better quality of life for individuals living with T1DM.

\section{Acknowledgements}

The author would like to acknowledge my healthcare practitioner Dr M. Moosajee for his willingness to assist me with this study.

\section{Competing interests}

The authors declare that they have no financial or personal relationships which may have inappropriately influenced them in writing this article.

\section{Author's contributions}

W.D. pursued this study for her Masters Dissertation and was the 1st author. M.M. supervised W.D. and was the co-author.

\section{Funding}

This research received no specific grant from any funding agency in the public, commercial, or not-for-profit sectors.

\section{Data availability statement}

Data sharing is not applicable to this article as no new data were created or analysed in this study.

\section{Disclaimer}

The views and opinions expressed in this article are those of the authors and do not necessarily reflect the official policy or position of any affiliated agency of the authors.

\section{References}

Aitken, M., 2013, Patient apps for improved healthcare: From novelty to mainstream viewed 13 July 2018, from https://developer.imshealth.com/Content/pdf/IIHI Patient_Apps_Report.pdf.

Arellano, P., Barnes, J., Bochinski, J., Marinak, C. \& Smelcer, J., 2012, 'Mobile apps for managing adolescent type 1 diabetes: Usability considerations, viewed 13 July 2018, from http://himss.files.cmsplus.com/FileDownloads/MobileAppsforManage AdolescentT1D-UsabilityConsiderations_Handouts.pdf.
Ben, W. \& Mearns, M.A., 2014, 'The use of mobile health applications by adolescents living with type 1 diabetes mellitus', in 12th Annual Information and Knowledge Management Conference, University of Johannesburg, Johannesburg, 27th November 2014.

Bental, D. \& Cawsey, A., 2002, 'Personalized and adaptive systems for medical consumer applications', Communications of the ACM 45(5), 62-63. https://doi. org/10.1145/506218.506248

Cafazzo, J.A., Casselman, M. \& Hamming, N., 2012, 'Design of an health app for the self-management of adolescent type 1 diabetes: A pilot study', Journal of Medical Internet Research 14(3), 1-14. https://doi.org/10.2196/jmir.2058

Chrisler, J. \& McCreary, D., 2010, Handbook of gender research in psychology, Springer, New York.

Clune, J.E., 2009, Heuristic evaluation functions for general game playing, ProQuest LLC, USA. Los Angeles, CA

Cohen, J.T. \& Zegarelli, B.M., 2017, Building a health app? Part 3: What you need to know about FDA's regulation of mobile apps, viewed 20 July 2018 , from https://www.lexology.com/library/detail.aspx?g=eb9a8691-79ae-424e-80d9$6717418 \mathrm{df} 270$.

Diabetes Coalition, 2016, Live better, live longer, viewed n.d., from http://www. sddiabetescoalition.org/.

Diabetes.co.uk, 2019, Children and diabetes, viewed 18 July 2018, from https://www. diabetes.co.uk/children-and-diabetes.html.

Eng, D.S. \& Lee, J.M., 2013, 'The promise and peril of mobile health applications for diabetes and endocrinology', Pediatric Diabetes 14(1), 231-238. https://doi. org/10.1111/pedi.12034

Eysenbach, G., 2011, 'Effects of mobile phone intervention for diabetes on glycaemia control', Journal of Medical Internet Research 13(3), 1-35. https://doi.org/ 10.2196/jmir.1923

Glesne, C., 2006, Becoming qualitative researchers: An introduction, Pearson, London.

Gordon, S., 2014, Smartphone apps for diabetes: Do they really work?, viewed n.d., from http://consumer.healthday.com/diabetes-information-10/blood-glucose-monitornews-69/smartphone-apps-for-diabetes-do-they-really-work-684002.html.

Goyal, S. \& Cafazzo, J.A., 2013, 'Mobile phone health apps for diabetes management: Current evidence and future developments', The Quarterly Journal of Medicine 106, 1067-1069. https://doi.org/10.1093/qjmed/hct203

Healio, 2018, Diabetes apps evolve to address individual health issues, goal, viewed 21 July 2018, from https://www.healio.com/endocrinology/news/online/\%7B1b2559e32438-4af8-a797-98772a508483\%7D/diabetes-apps-evolve-to-address-individualhealth-issues-goals.

Kendall, H.O., 2013, 'Health-e-apps: A project to encourage effective use of mobile health applications', BC Medical Journal 55(10), 458-460.

Liang, X., Wang, Q., Yang, X., Cao, J., Chen, J., Mo, X. et al., 2011, 'Effect of mobile phone intervention for diabetes on glycaemic control: A meta-analysis', Diabetic Medicine 28(4), 455-463. https://doi.org/10.1111/j.1464-5491.2010.03180.x

Liquid State, 2018, The rise of mHealth apps: A market snapshot, viewed 18 July 2018, from https://liquid-state.com/mhealth-apps-market-snapshot/.

Quinn, C., 2011, 'American diabetes association standards', Diabetes Care 34(9), 1934-1942. https://doi.org/10.2337/dc11-0366

Ross, A., 2018, The mobile phone is dying, but mobile technology is just beginning, viewed n.d., from https://www.information-age.com/mobile-phone-technology123473365\%.

Schulke, D.F., 2013, 'The regulatory arms race: Mobile-health applications and agency posturing', Boston University Law Review 93(1), 1699-1752.

Thornby, K. \& Edquist, N., 2013, Diabetes apps: Impacting patients lives, viewed 22 July 2018, from http://www.ajmc.com/journals/evidence-based-diabetesmanagement/2013/2013-1-vol19-sp5/diabetes-apps-impacting-patients-livesmaximizing-the-use-of-mobile-applications-for-patients-with-diabetes-mellitus.

Tran, J., Tran, R. \& White, R., 2012, 'Smartphone-based glucose monitors and applications in the management of diabetes: An overview of 10 salient "Apps" and a novel smartphone-connected blood glucose monitor', Clinical Diabetes 30(4), 173-178. https://doi.org/10.2337/diaclin.30.4.173

World Health Organization (WHO), 2019, Diabetes, viewed 18 July 2018, from https:// www.who.int/news-room/fact-sheets/detail/diabetes. 